\title{
Distinct Cortical Anatomy Linked to Subregions of the Medial Temporal Lobe Revealed by Intrinsic Functional Connectivity
}

\section{Citation}

Kahn, I., J. R. Andrews-Hanna, J. L. Vincent, A. Z. Snyder, and R. L. Buckner. 2008. Distinct cortical anatomy linked to subregions of the medial temporal lobe revealed by intrinsic functional connectivity. Journal of Neurophysiology 100. no. 1: 129-139.

\section{Published Version}

http://dx.doi.org/10.1152/jn.00077.2008

\section{Permanent link}

http://nrs.harvard.edu/urn-3:HUL.InstRepos:3841548

\section{Terms of Use}

This article was downloaded from Harvard University's DASH repository, and is made available under the terms and conditions applicable to Other Posted Material, as set forth at http:// nrs.harvard.edu/urn-3:HUL.InstRepos:dash.current.terms-of-use\#LAA

\section{Share Your Story}

The Harvard community has made this article openly available.

Please share how this access benefits you. Submit a story.

\section{Accessibility}


Itamar Kahn, Jessica R. Andrews-Hanna, Justin L. Vincent, Abraham Z. Snyder and Randy L. Buckner

J Neurophysiol 100:129-139, 2008. First published Apr 2, 2008; doi:10.1152/jn.00077.2008

You might find this additional information useful...

Supplemental material for this article can be found at:

http://jn.physiology.org/cgi/content/full/00077.2008/DC1

This article cites 68 articles, 18 of which you can access free at:

http://jn.physiology.org/cgi/content/full/100/1/129\#BIBL

This article has been cited by 7 other HighWire hosted articles, the first 5 are:

L-Dopa Modulates Functional Connectivity in Striatal Cognitive and Motor Networks: A Double-Blind Placebo-Controlled Study

C. Kelly, G. de Zubicaray, A. Di Martino, D. A. Copland, P. T. Reiss, D. F. Klein, F. X.

Castellanos, M. P. Milham and K. McMahon

J. Neurosci., June 3, 2009; 29 (22): 7364-7378.

[Abstract] [Full Text] [PDF]

Posterior parietal cortex and episodic retrieval: Convergent and divergent effects of attention and memory

J. B. Hutchinson, M. R. Uncapher and A. D. Wagner

Learn. Mem., May 23, 2009; 16 (6): 343-356.

[Abstract] [Full Text] [PDF]

On the nature of medial temporal lobe contributions to the constructive simulation of future events

D. L. Schacter and D. R. Addis

Phil Trans R Soc B, May 12, 2009; 364 (1521): 1245-1253.

[Abstract] [Full Text] [PDF]

Brain Activation during Anticipation of Sound Sequences

A. M. Leaver, J. Van Lare, B. Zielinski, A. R. Halpern and J. P. Rauschecker

J. Neurosci., February 25, 2009; 29 (8): 2477-2485.

[Abstract] [Full Text] [PDF]

The Resting Brain: Unconstrained yet Reliable

Z. Shehzad, A. M. C. Kelly, P. T. Reiss, D. G. Gee, K. Gotimer, L. Q. Uddin, S. H. Lee, D. S. Margulies, A. K. Roy, B. B. Biswal, E. Petkova, F. X. Castellanos and M. P. Milham

Cereb Cortex, February 16, 2009; 0 (2009): bhn256v1-bhn256.

[Abstract] [Full Text] [PDF]

Updated information and services including high-resolution figures, can be found at:

http://jn.physiology.org/cgi/content/full/100/1/129

Additional material and information about Journal of Neurophysiology can be found at: http://www.the-aps.org/publications/jn

This information is current as of July 2, 2009 . 


\title{
Distinct Cortical Anatomy Linked to Subregions of the Medial Temporal Lobe Revealed by Intrinsic Functional Connectivity
}

\author{
Itamar Kahn, ${ }^{1,2,3}$ Jessica R. Andrews-Hanna, ${ }^{1,2}$ Justin L. Vincent, ${ }^{1,2}$ Abraham Z. Snyder, ${ }^{4}$ \\ and Randy L. Buckner ${ }^{1,2,3}$ \\ ${ }^{1}$ Department of Psychology and Center for Brain Science, Harvard University, Cambridge, Massachusetts; ${ }^{2}$ Athinoula A. Martinos Center \\ for Biomedical Imaging, Massachusetts General Hospital, Charlestown, Massachusetts; ${ }^{3}$ Howard Hughes Medical Institute, ${ }^{4}$ Mallinckrodt \\ Institute of Radiology and Department of Neurology Washington University School of Medicine, St. Louis, Missouri
}

Submitted 22 January 2008; accepted in final form 27 March 2008

\begin{abstract}
Kahn I, Andrews-Hanna JR, Vincent JL, Snyder AZ, Buckner RL. Distinct cortical anatomy linked to subregions of the medial temporal lobe revealed by intrinsic functional connectivity. J Neurophysiol 100: 129-139, 2008. First published April 2, 2008; doi:10.1152/jn.00077.2008. The hippocampus and adjacent cortical structures in the medial temporal lobe (MTL) contribute to memory through interactions with distributed brain areas. Studies of monkey and rodent anatomy suggest that parallel pathways converge on distinct subregions of the MTL. To explore the cortical areas linked to subregions of the MTL in humans, we examined cortico-cortical and hippocampal-cortical correlations using high-resolution, functional connectivity analysis in 100 individuals. MTL seed regions extended along the anterior to posterior axis and included hippocampus and adjacent structures. Results revealed two separate brain pathways that correlated with distinct subregions within the MTL. The body of the hippocampus and posterior parahippocampal cortex correlated with lateral parietal cortex, regions along the posterior midline including posterior cingulate and retrosplenial cortex, and ventral medial prefrontal cortex. By contrast, anterior hippocampus and the perirhinal/ entorhinal cortices correlated with distinct regions in the lateral temporal cortex extending into the temporal pole. The present results are largely consistent with known connectivity in the monkey and provide a novel task-independent dissociation of the parallel pathways supporting the MTL memory system in humans. The cortical pathways include regions that have undergone considerable areal expansion in humans, providing insight into how the MTL memory system has evolved to support a diverse array of cognitive domains.
\end{abstract}

\section{N T R O D U C T I O N}

Declarative memory-conscious memory for events and facts-depends on the medial temporal lobe (MTL) (Cohen and Eichenbaum 1993; Milner et al. 1968; Squire 1992). The MTL encompasses anatomically related structures including the hippocampal formation and adjacent parahippocampal, perirhinal, and entorhinal cortices, which lie along the parahippocampal gyrus (collectively referred to as the parahippocampal region) (see Witter et al. 2000). The complex anatomy of the MTL has led to a debate about the nature of the contributions of subregions of the MTL and whether they are associated with functionally distinct processes or act collectively as an integrated system (e.g., Eichenbaum et al. 2007; Squire et al. 2004).

Address for reprint requests and other correspondence: I. Kahn, Howard Hughes Medical Institute at Harvard University, 33 Kirkland St., WJH 270, Cambridge, MA 02138 (E-mail: kahn@nmr.mgh.harvard.edu).
The neocortical connections of parahippocampal and perirhinal cortices are complementary (Burwell and Amaral 1998; Suzuki and Amaral 1994a). Both the parahippocampal and perirhinal cortices feed information into the entorhinal cortex. The parahippocampal cortex projects largely to the medial entorhinal area, whereas the perirhinal projects largely to the lateral entorhinal area. The entorhinal cortex, in turn, projects to the hippocampal formation. These parallel pathways, however, are interconnected with a substantial projection from parahippocampal cortex to perirhinal cortex, in addition to connections between the lateral and medial areas of the entorhinal cortex. Thus the anatomy of the cortico-parahippocampal-hippocampal system is best described as including both parallel and hierarchical components, positioning it well to integrate diverse informational sources important to memory (Burwell 2000; Furtak et al. 2007; Lavenex and Amaral 2000; Witter et al. 2000).

The centrality of the MTL memory system extends to its connectivity with the broader neocortex. Multiple uni- and polymodal cortical regions project to the parahippocampal and perirhinal cortices (Burwell and Amaral 1998; Schmahmann and Pandya 2006; Suzuki and Amaral 1994a). The cortical projections encompass two parallel pathways. The parahippocampal cortex receives inputs from visual association areas, retrosplenial cortex, the dorsal bank of the superior temporal sulcus, and the parietal lobe, among other regions. The perirhinal cortex receives inputs including from visual areas in the ventral temporal cortex and the ventral and dorsal banks of the superior temporal sulcus (Lavenex and Amaral 2000; Suzuki and Amaral 1994a,b). These two pathways have been heuristically characterized as relating to spatial and nonspatial aspects of sensory input because of their preferential connections to parietal areas (parahippocampal pathway) and inferior temporal areas (perirhinal pathway). While initial evidence suggests homologies between human and macaque (Catani et al. 2003), important differences may also exist especially in cortical regions with substantial areal expansion in humans (Van Essen and Dierker 2007). Thus, detailed characterization of pathways linked to subregions within the MTL is essential for further progress. Specifically, it is unknown whether human MTL shows regional differentiation that supports two parallel pathways and, if present, whether the cortical targets of the parallel pathways are best characterized as sensory systems.

\footnotetext{
The costs of publication of this article were defrayed in part by the payment of page charges. The article must therefore be hereby marked "advertisement" in accordance with 18 U.S.C. Section 1734 solely to indicate this fact.
} 

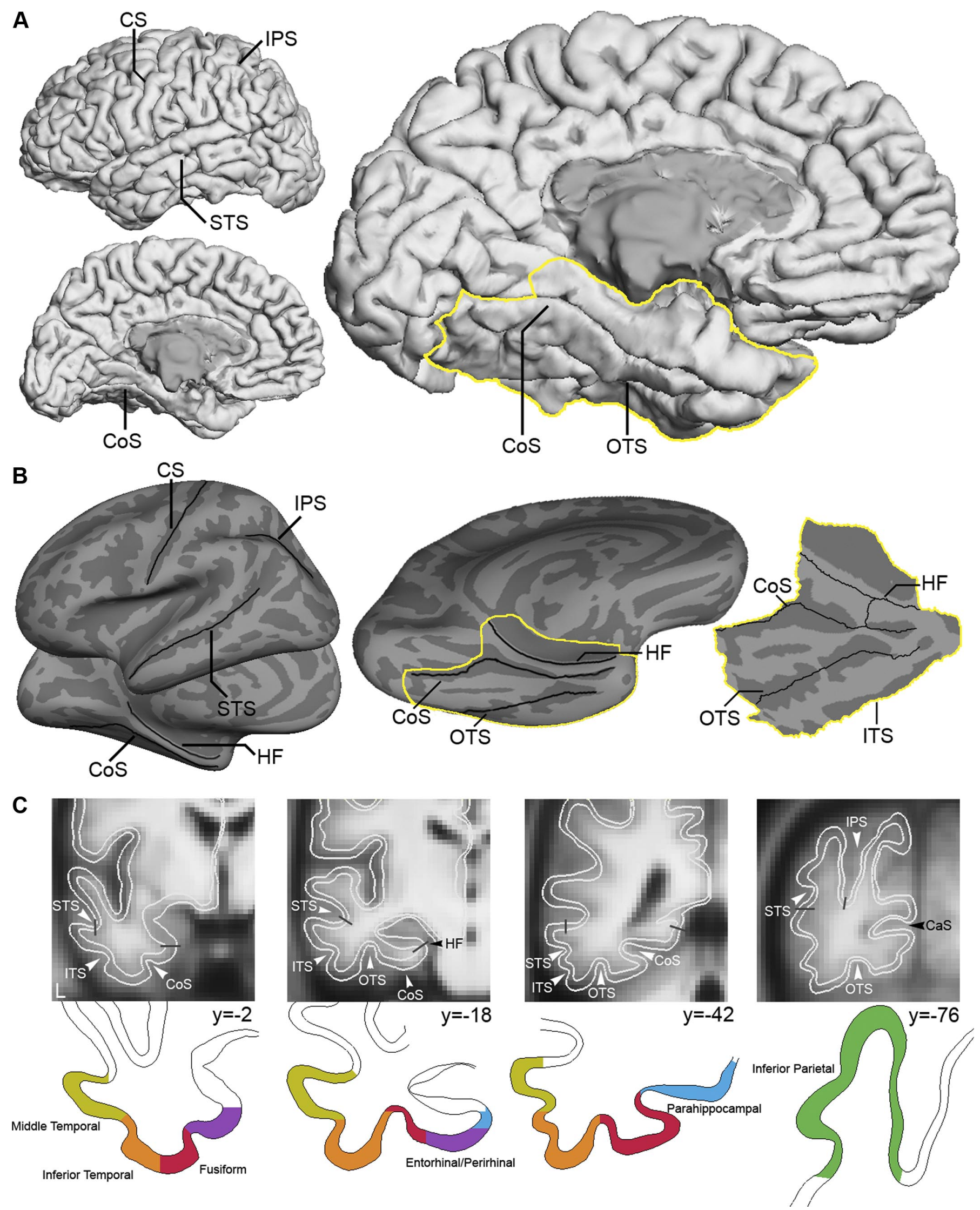
Methods based on intrinsic activity have recently emerged as powerful tools to explore human functional connectivity. Spontaneous activity patterns in the cortex have been shown to reflect functional-anatomic organization of the brain both at the level of cortical columns (Arieli et al. 1995; Kenet et al. 2003; Moon et al. 2007) and large-scale functional networks spanning multiple cortical regions (e.g., Biswal et al. 1995; De Luca et al. 2006; Fox et al. 2005, 2006; Greicius et al. 2003; Vincent et al. 2006; for review, see Fox and Raichle 2007). In macaques, low-frequency $(<0.1 \mathrm{~Hz})$ spontaneous blood oxygenation level-dependent (BOLD) signal fluctuations measured with MRI have been shown to correspond to functional activation and polysynaptic anatomical connectivity patterns (Vincent et al. 2007). These correlations likely involve a combination of direct and indirect anatomic connectivity. While the physiological significance of the BOLD fluctuations remains incompletely understood, they provide a powerful means of exploring functional connectivity in humans (for recent review, see Fox and Raichle 2007). Previous studies using functional connectivity have revealed that the MTL is correlated with widespread regions of cortex, but the anatomic resolution of past techniques has not allowed for detailed analysis of subregions within the MTL (Greicius et al. 2004; Vincent et al. 2006). Thus it is unknown whether humans possess multiple parallel pathways that converge on distinct subregions of the MTL as would be predicted from anatomic studies in the macaque.

The present work sought to delineate the functional connectivity of the MTL to test the hypothesis that distinct cortical regions comprising multiple parallel pathways converge on subregions of the MTL. To identify the pathways connected to the MTL, we computed correlation maps of spontaneous lowfrequency fluctuations in the BOLD signal acquired using high-resolution imaging methods in the absence of overt task performance. We identified two distinct cortical pathways that each reliably correlated with separate subregions of the MTL memory system.

\section{METHODS}

\section{Participants}

One hundred adults [ 58 females; ages $18-34$, mean age: $22.9 \pm 4.3$ (SD) yr] participated. All participants had normal or corrected-tonormal vision and were right-handed, native English speakers. Participants were screened to exclude individuals with a history of neurologic or psychiatric conditions as well as those using psychoactive medications. Informed consent was obtained in accordance with guidelines set forth by the institutional review board of the Massachusetts General Hospital.

\section{Data acquisition and preprocessing}

Scanning was performed on a 3T TimTrio system (Siemens, Erlangen, Germany) using a 12-channel phased-array head coil. High- resolution three-dimensional (3D) T1-weighted magnetization prepared rapid acquisition gradient echo (MP-RAGE) anatomical images were collected $\left(\mathrm{TR}=2,530 \mathrm{~ms}, \mathrm{TE}=3.39 \mathrm{~ms}, \mathrm{FA}=7^{\circ}, 1 \times 1 \times\right.$ $1.33 \mathrm{~mm}$ voxels). Functional data were acquired using a gradient-echo echo-planar pulse sequence $\left(\mathrm{TR}=5,000 \mathrm{~ms}, \mathrm{TE}=30 \mathrm{~ms}, \mathrm{FA}=90^{\circ}\right.$, 55 axial slices, $2 \times 2 \times 2 \mathrm{~mm}$ voxels, no interslice gap, FOV $256 \times$ $256 \mathrm{~mm}$, matrix size of $128 \times 128)$. The relatively long TR $(5 \mathrm{~s})$ enabled whole brain coverage with high spatial resolution. Because functional connectivity analysis is based on low-frequency fluctuations $(<0.1 \mathrm{~Hz})$, sparse temporal sampling is sufficient. As will be shown, robust intrinsic correlations were observed consistent with prior observations using shorter TR. Head motion was restricted using a pillow and foam inserts that surrounded the head and earplugs were used to attenuate scanner noise.

Two separate data sets (Data Set 1: $n=55$; Data Set 2: $n=45$ ) were acquired with similar parameters with the exception of total time points (Data Set 1: 2 runs $\times 65$ time points; Data Set 2: 4 runs $\times 76$ time points). Additional runs were acquired at the same session but not included in present analyses. In Data Set 1, a visual face detection task (lasting $\sim 20 \mathrm{~min}$ ) preceded the fixation runs, and a face recognition memory task (45 min) followed it. In Data Set 2, two fixation runs were administered at the beginning of the scanning session. The remaining two fixation runs were administered near the end of the scanning session, approximately an hour later. During the intervening hour, participants completed two behavioral tasks making judgments about mental states of characters in visually presented short stories and a recognition memory task of visually presented words.

The two independent data sets allowed us to test the reliability of the functional correlation maps. Specifically, we used Data Set 1 to identify in an exploratory manner the distinct cortical regions that are correlated with subregions of the MTL. Data Set 2 was used to test predictions generated by the initial data set and to compare the topography of independently obtained correlation maps.

Participants were instructed only to fixate on a visual crosshair centered on a screen for the entire duration of all the fixation runs. The visual stimulus was generated on an Apple PowerBook G4 computer (Apple, Cupertino, CA) using Matlab (The Mathworks, Natick, MA) and the Psychophysics Toolbox extensions (Brainard 1997). The stimulus was projected onto a screen positioned at the head of the magnet bore.

Resting-state data were preprocessed using procedures common in conventional fMRI studies to reduce scanner artifacts, correct for head motion, and transform the data into a standard atlas space. These preprocessing steps included removal of the first four volumes to allow for T1-equilibration effects, compensation of systematic, slicedependent time shifts (SPM2, Wellcome Department of Cognitive Neurology, London, UK), and rigid body correction for head motion within and across runs (Jenkinson et al. 2002; FMRIB, Oxford, UK). The last step provided a record of head position within functional runs that was later used as a nuisance regressor in the correlation analysis (see following text). Atlas registration was achieved by computing affine transforms connecting the first image volume of the first functional run with the T1-weighted structural images (Jenkinson and Smith 2001; FMRIB, Oxford, UK). Our atlas representative template includes MP-RAGE data from 12 normal individuals and was made to conform to the Montreal Neurological Institute (MNI) template using previously described methods (Buckner et al. 2004). The final preprocessing step combined motion correction and atlas transformation

FIG. 1. Major anatomic landmarks in the parietal, temporal, and medial temporal lobes. A: reconstructed cortical representation of a typical participant

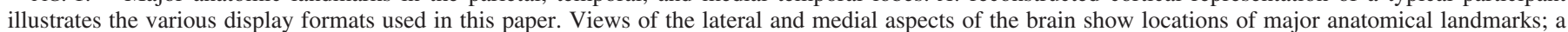

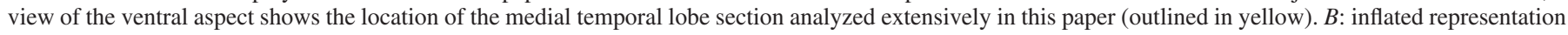

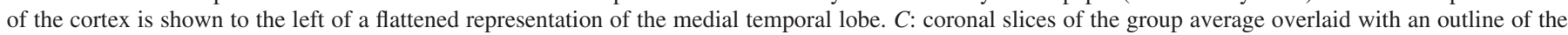

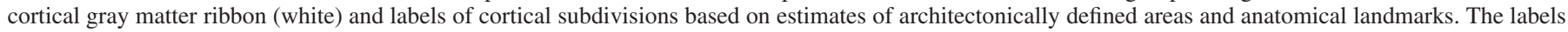

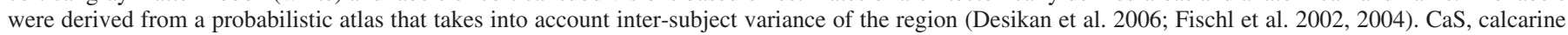

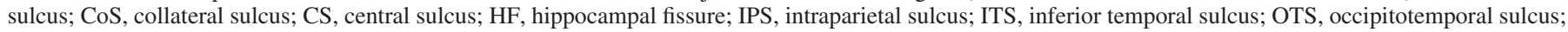
STS, superior temporal sulcus. 

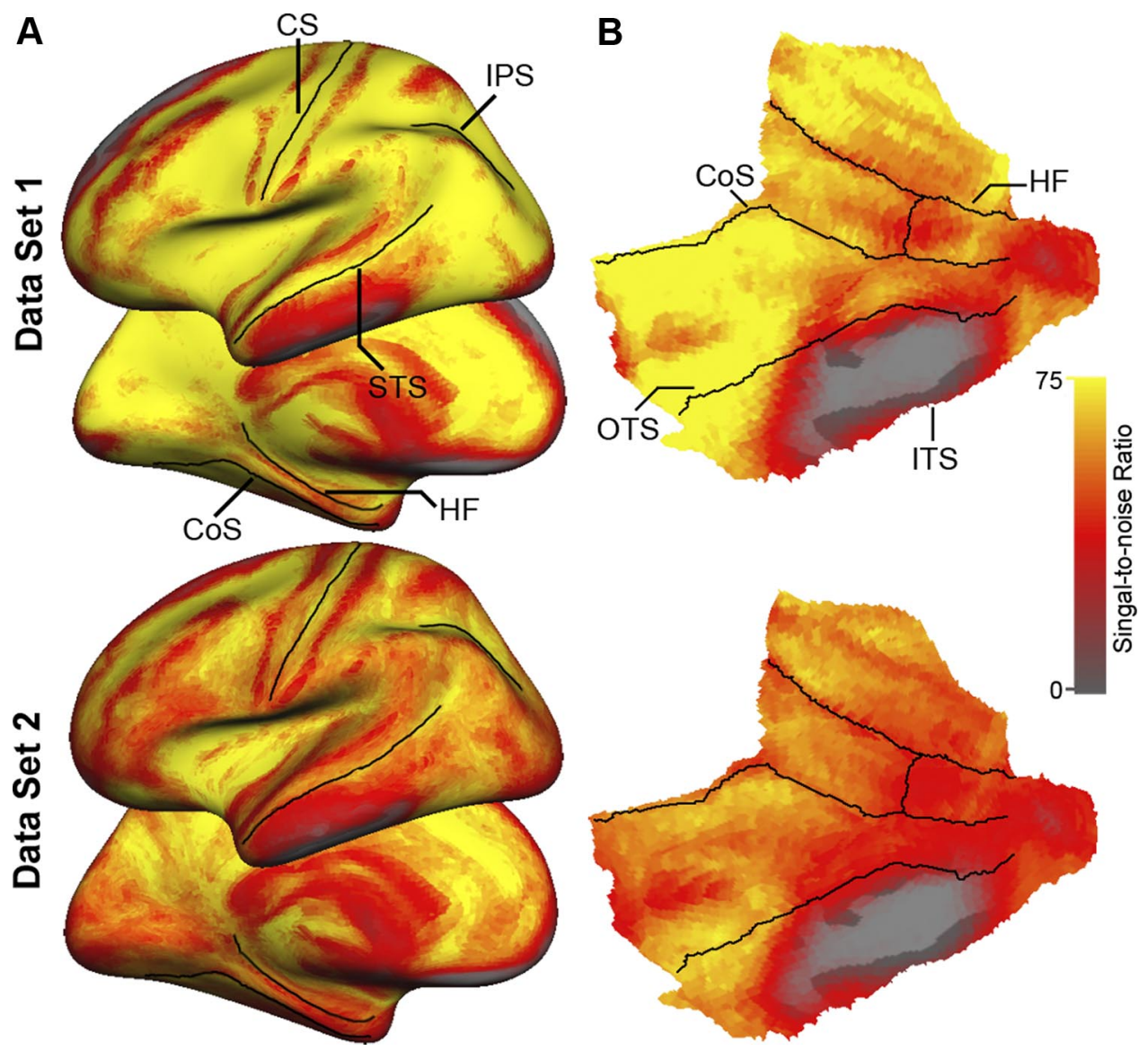

FIG. 2. Signal-to-noise estimates for the present 2 data sets. $A$ : lateral and medial views depict relatively uniform signal-to-noise across the 2 groups. $B$ : flattened representation of the medial temporal lobe demonstrates that signal dropout is predominant between the occipitotemporal and inferior temporal sulci. Formats of the surface representations are illustrated in Fig. 1.

in one step to yield a motion-corrected volumetric time series sampled at 2 -mm cubic voxels.

regions where the brain is adjacent to air or dense bone. Regions in the MTL immediately above the petrous bone are particularly prone to signal loss (Ojemann et al. 1997). To estimate the effects of susceptibility artifacts in the present data, the signal-to-noise ratio (SNR) was computed for each voxel by averaging the signal intensity across the whole run and dividing it by the SD over time. The SNR was computed for all the target-atlas normalized BOLD runs acquired for each participant and averaged to provide a single value for each voxel in the brain. The SNR was computed separately for Data Set 1 and Data Set 2. As can be observed in Fig. 2, low SNR is present in the anterior portion of the inferior temporal and orbitofrontal cortices. Importantly, signal loss in the MTL was restricted to the same regions across the two data sets, with good to excellent SNR present for most portions of the MTL including the body and head of the hippocampus. atlas that incorporates probable location of a region intersubject variance of the region. Specifically, a probabilistic labeling algorithm (Fischl et al. 2004) was used with a training set comprised of manually identified 34 cortical ROIs in each of the individual hemispheres from 40 MRI scans (Desikan et al. 2006; see also Fischl et al. 2002). The overlap of the cortical ribbons on the group average of participants in Data Set 1 with the estimated anatomical subdivisions of the MTL including the hippocampus were then computed (Desikan et al. 2006; Fischl et al. 2002, 2004). In addition, the results from both data sets were projected onto the inflated surface of the left cerebral hemisphere of the average fiducial PALS surface (Supplementary Fig. $\mathrm{S}^{1}$ ) using Caret software (Van Essen 2005) to allow comparison to earlier work (e.g., Vincent et al. 2006).

\section{Assessment of susceptibility artifacts}

Signal loss and distortion (susceptibility artifacts) in $\mathrm{T}_{2}{ }^{*}$-dependent (BOLD) images occur as a result of magnetic inhomogeneities in

\footnotetext{
${ }^{1}$ The online version of this article contains supplemental data.
}

\section{Group functional connectivity analysis}

Functional connectivity analysis was achieved following the preprocessing and correlation procedures used by Fox and colleagues (2005) and detailed in Vincent et al. (2006). Briefly, the preprocessed functional data (in atlas space) were passed through an additional series of processing steps. First, for each voxel, temporal filtering removed constant offsets and linear trends over each run while retaining frequencies $<0.08 \mathrm{~Hz}$. Data were spatially smoothed using a 4-mm full-width half-maximum Gaussian blur. Several sources of spurious or regionally nonspecific variance were then removed by regression of nuisance variables including: six parameters obtained by rigid body head motion correction, the signal averaged over the whole-brain, the signal averaged over the lateral ventricles, and the signal averaged over a region centered in the deep cerebral white matter. Temporally shifted versions of these waveforms also were removed by inclusion of the first temporal derivatives (computed by backward differences) in the linear model. This regression procedure 
removes variance unlikely to represent regionally specific correlations of neuronal origin. Of note, the global (whole-brain) signal correlates with respiration-induced fMRI signal fluctuations (Birn et al. 2006; Wise et al. 2004). By removing global signal, variance contributed by physiological artifacts is minimized and the distribution of correlation coefficients throughout the brain are set such that there are equal number of positive and negative correlations. Consequently, testing a positive correlation coefficient for statistical significance against the null hypothesis of no correlation $(r=0)$ becomes appropriate (Vincent et al. 2006). Removal of signals correlated with ventricles and white matter further reduces nonneuronal contributions to BOLD correlations (Bartels and Zeki 2005; Fox et al. 2005).

Correlation maps for each seed in the left hemisphere were computed by correlating regional time courses (averaged over all voxels within the seed region) with every voxel in the brain. Correlation maps were converted to $z$ maps using Fisher's $r$-to- $z$ transformation (Zar 1996). This transformation generates values for each voxel that are approximately normally distributed across individuals in a homogenous population. Individual $z$ maps were entered into conventional random effects analyses to obtain $t$-maps representing regions reliably correlated across the whole group. The $t$-maps were computed for each data set and thresholded at $P<0.001$ (uncorrected for multiple comparisons). Effects were interpreted only if they were identified in Data Set 1 and then independently replicated in Data Set 2. This experimental strategy provides an unbiased measurement of correlation strength and employs a conservative solution to the problem of multiple comparisons (Buckner et al. 1995; Vincent et al. 2006).

\section{Construction of MTL seed regions of interest}

The objective of the correlation analysis was to identify regions of cortex intrinsically correlated with subregions of the hippocampus and surrounding MTL structures (similar to the analysis of anterior cingulate cortex by Margulies et al. 2007). The seed regions were spheres ( $3 \mathrm{~mm}$ radius; 7 voxels $\times 2 \mathrm{~mm}^{3}=56 \mathrm{~mm}^{3}$ volume) centered on coordinates in stereotaxic atlas space obtained by creating an average T1 image from the group of participants in Data Set 1. A total of 16 seeds were defined in the left hemisphere. A set of eight seeds separated center-to-center by $4 \mathrm{~mm}$ (Table 1 and Fig. 3) spanned the long axis of the hippocampus, and an additional set of eight seeds spanned the collateral sulcus. Thus these seed regions afforded full coverage of the MTL. For visualization purposes, the seed region centers are represented in Fig. 3 as dots on the flattened MTL surface.

\section{R E S U L T S}

\section{Subregions within the MTL correlate with distinct cortical pathways}

Correlation maps corresponding to the parahippocampal and perirhinal/entrorhinal cortices are shown for Data Set 1 (Fig. 4). A seed located in the perirhinal/entorhinal cortices (PRc/ERc) correlated with the lateral anterior temporal lobe immediately below the superior temporal sulcus (Fig. 4A). In contrast, a seed located in the posterior portion of the parahippocampal cortex (PHc) strongly correlated with the inferior parietal lobule, retrosplenial cortex extending into posterior cingulate, and ventral medial prefrontal cortex (Fig. 4B). Two important aspects of these maps are evident in Fig. 4. First, the maps are nonoverlapping with the exception of a small region in the anterior temporal pole and a larger region in the MTL along the collateral sulcus and toward the head of the hippocampus/ amygdala (likely attributable to high local connectivity and autocorrelation around the seed). Second, as can be seen on the coronal slices in Fig. 4 (see also Fig. 5), the correlation maps
TABLE 1. Seed regions of interest

\begin{tabular}{|c|c|c|c|c|}
\hline & $x$ & $y$ & $z$ & \\
\hline \multirow[t]{8}{*}{ Hipp seeds } & -22 & -38 & 0 & \\
\hline & -22 & -34 & -6 & \\
\hline & -26 & -30 & -10 & \\
\hline & -26 & -26 & -12 & \\
\hline & -26 & -22 & -14 & \\
\hline & -24 & -18 & -18 & bHipp (1)* \\
\hline & -24 & -14 & -20 & \\
\hline & -24 & -10 & -22 & hHipp (2) \\
\hline \multirow[t]{5}{*}{ PHc seeds } & -26 & -40 & -12 & PHc (3) \\
\hline & -26 & -36 & -16 & \\
\hline & -26 & -32 & -18 & \\
\hline & -26 & -28 & -22 & \\
\hline & -26 & -24 & -26 & \\
\hline \multirow[t]{3}{*}{ PRc/ERc seeds } & -26 & -20 & -30 & PRc/ERc (4) \\
\hline & -26 & -16 & -34 & \\
\hline & -26 & -10 & -34 & \\
\hline \multicolumn{5}{|l|}{ Peak Hipp correlated regions } \\
\hline Lateral inferior parietal lobule & -44 & -78 & 38 & IPL (1) \\
\hline Anterior inferior temporal sulcus & -50 & -2 & -32 & $\operatorname{aITS}(2)$ \\
\hline \multicolumn{5}{|l|}{ Peak PHc correlated regions } \\
\hline Lateral inferior parietal lobule & -38 & -76 & 38 & (3) \\
\hline \multicolumn{5}{|l|}{ Peak PRc/ERc correlated regions } \\
\hline Anterior inferior temporal sulcus & -54 & -16 & -16 & (4) \\
\hline
\end{tabular}

aITS, anterior inferior temporal sulcus; bHipp, body of the hippocampus; ERc, entorhinal cortex; hHipp, head of the hippocampus; Hipp, hippocampus; IPL, inferior parietal lobule; PHc, parahippocampal cortex; PRc, perirhinal cortex. *Anatomically defined seeds in the medial temporal lobe and corresponding peak correlation seeds are denoted.

were largely symmetric even though the seeds were unilateral (consistent with Vincent et al. 2006). Additional seed regions along the collateral sulcus yielded correlation maps similar to one or the other of these two maps or a combination of both but did not reveal additional cortical networks (not shown).

Seed regions located in the hippocampus revealed similarly distinct correlation maps. A seed in the mid portion of the body of the hippocampus (bHipp) revealed a pattern similar to that observed with the PHc seed (Fig. 5), whereas a seed located in the head of the hippocampus (hHipp) revealed a pattern similar to that obtained with the PRc/ERc seed (not shown). To compare our maps to prior work, we also projected the left cerebral hemisphere onto the average fiducial PALS surface using Caret software (Van Essen 2005). The two sets of cortical regions generated by the hippocampal seeds, when combined, correspond closely to the cortical system reported in Vincent et al. (2006) (see Supplementary Fig. S1). Further, as demonstrated in Fig. 5, seeds adjacent in the hippocampus and PRc/ERc yielded two distinct maps implying that the two cortical pathways are associated with nearby, but separate, subregions of the MTL. The next sections explore this possibility directly.

\section{Identification of a priori cortical regions for hypothesis testing}

The maps generated by the hippocampal seeds (bHipp and hHipp) in Data Set 1 were used to define cortical regions used as a priori seeds in Data Set 2 (Buckner et al. 1995; Vincent et al. 2006). A central goal of this analysis was to identify distinct cortical regions differentially correlated with hHipp and PRc/ERc versus bHipp and PHc. As described in the preceding text, in Data Set 1, the anterior inferior temporal sulcus (aITS) and inferior parietal lobule (IPL) selectively corre- 

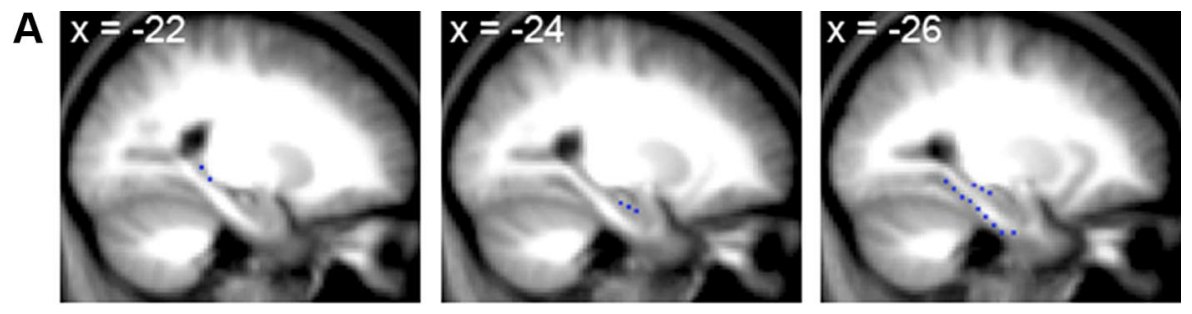

B

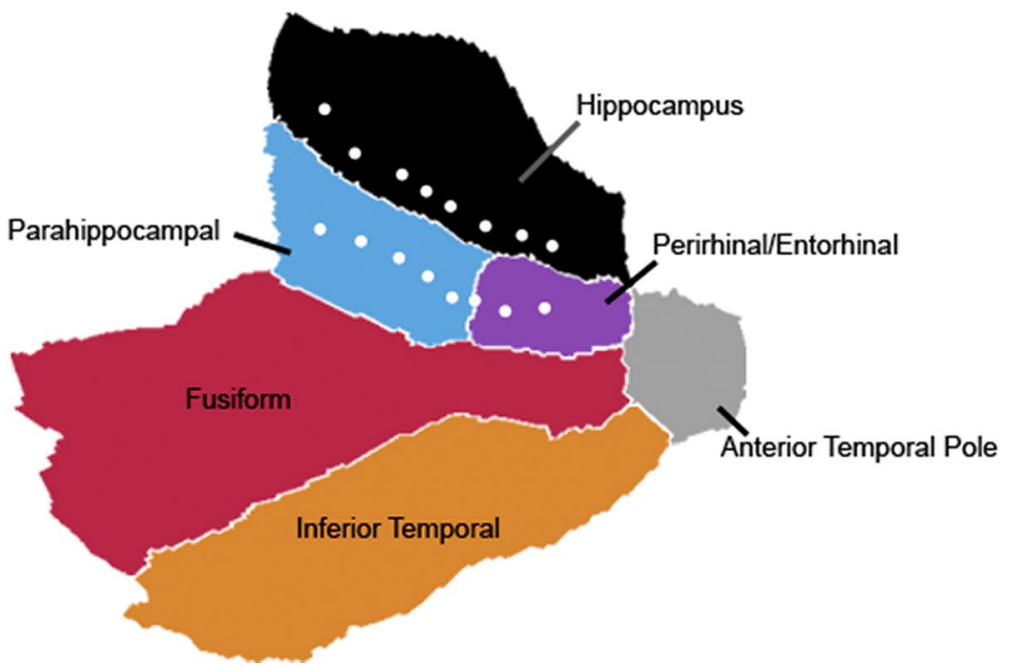

FIG. 3. Seed regions in the medial temporal lobe of the left hemisphere. A: sagittal slices of the group-averaged structural images depict the seed locations (blue dots) along the long axis of the hippocampus and the collateral sulcus. $B$ : a flattened patch of the medial temporal lobe is shown with the 16 seed locations (white dots) depicted. The seeds cover the hippocampus and the medial temporal lobe including the parahippocampal and perirhinal/entorhinal cortices. Coordinates here and elsewhere refer to the atlas coordinate system of the Montreal Neurological Institute (MNI) template (see text). lated with distinct seeds in the MTL (Fig. 5). Local maxima were identified in aITS and IPL from the correlation maps associated with hHipp and bHipp, respectively. Regions defined around these peaks (8-mm radius spheres) were carried forward for analysis of Data Set 2.
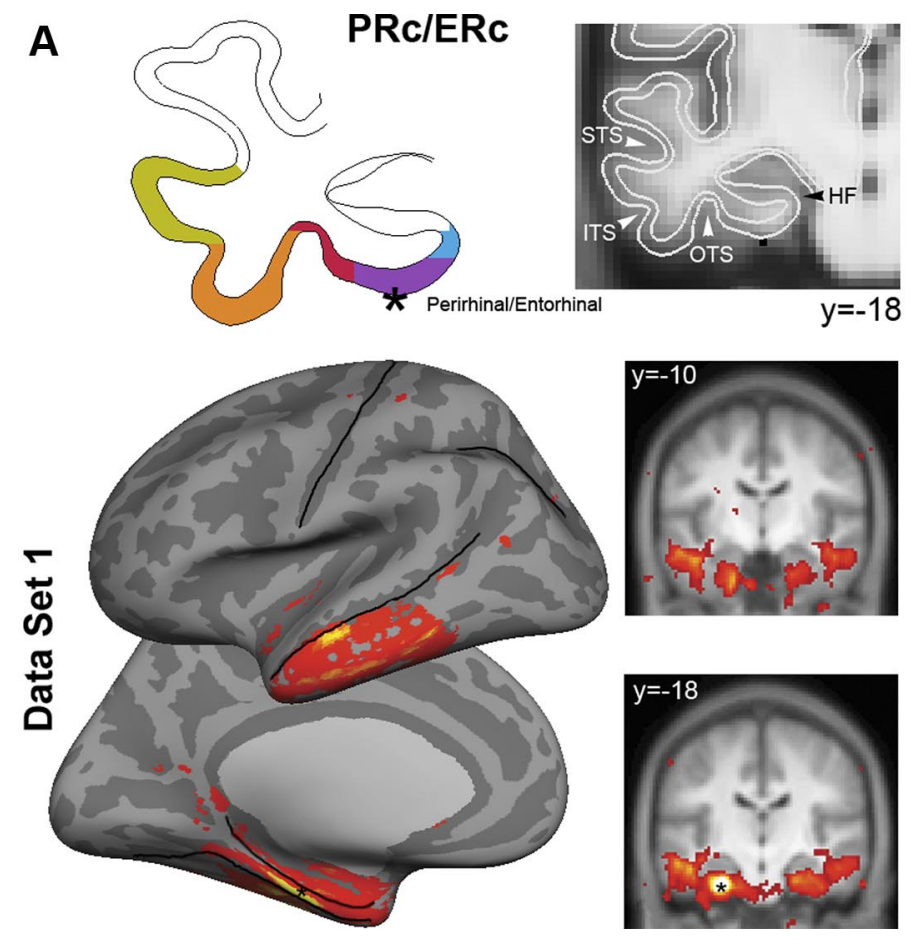

aITS and IPL correlate with distinct subregions of the MTL

Depicted in Fig. 6 are the locations of the aITS and IPL seeds predicted to dissociate MTL subregions and the MTL correlation maps for each of these two cortical seeds. Results
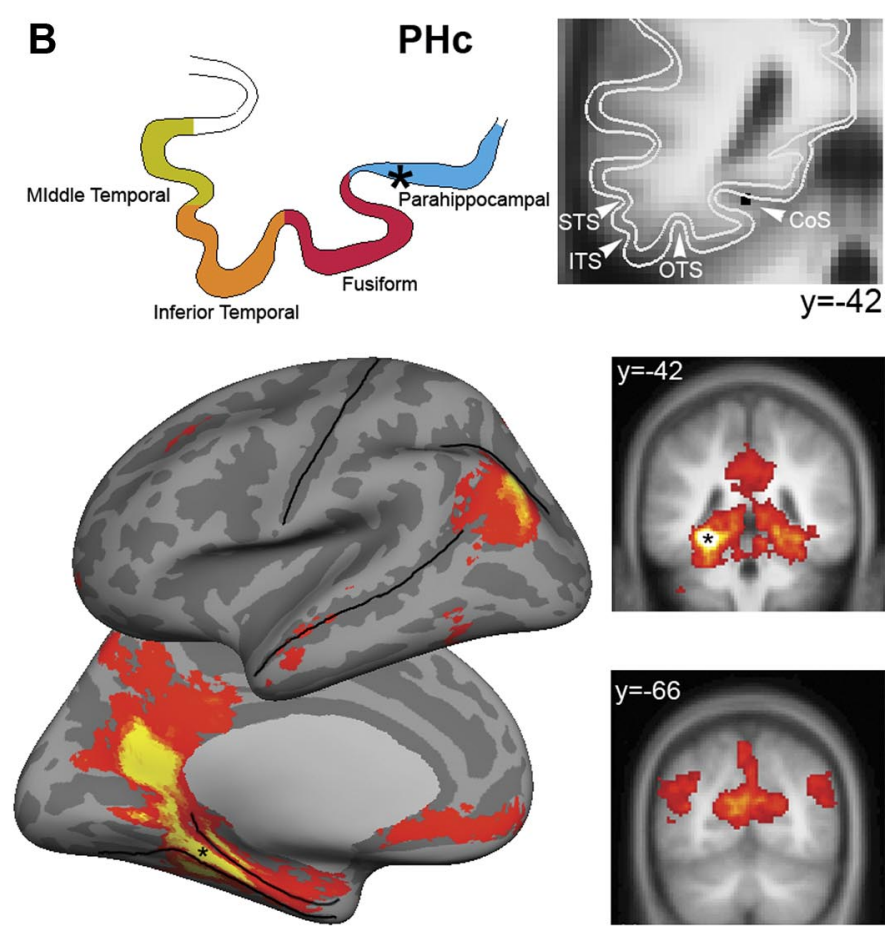

FIG. 4. Distinct cortical regions are correlated with the perirhinal/entorhinal cortices (PRc/ERc) and parahippocampal cortex (PHc). Correlation maps are illustrated for 2 seed regions along the collateral sulcus. PRc/ERc (MNI coordinates [ $-26-20-30]$ ) and PHc $([-26-40-12])$ seeds defined as 3-mm spheres are depicted on coronal slices of group-averaged structural image. An outline of the cortical gray matter is depicted on the left. Seed locations are depicted in black on coronal slices and as black stars on the cortical ribbon outline. Correlation maps were obtained after within-subject transformation using Fisher's r-to-z and submitted for a second level analysis using a random effects model (threshold $P<0.001$ ). Two distinct patterns of correlated activity were observed. $A$ : the PRc/ERc correlated with the anterior aspect of the lateral temporal lobe. $B$ : in contrast, the PHc was correlated with lateral and medial parietal and ventral medial prefrontal cortices. 

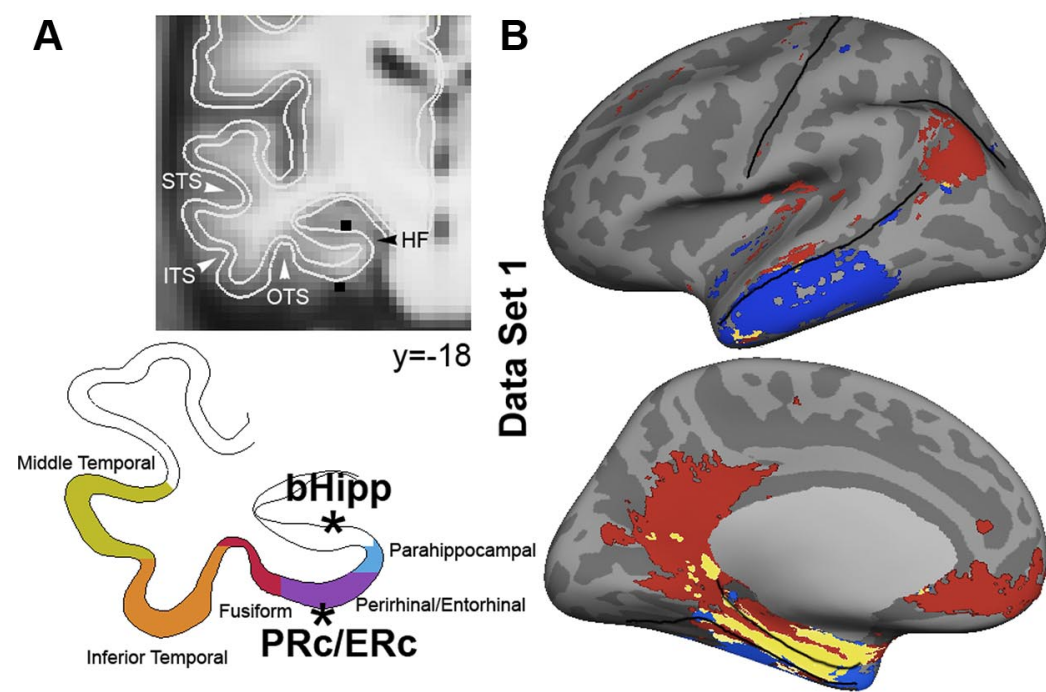

bHipp

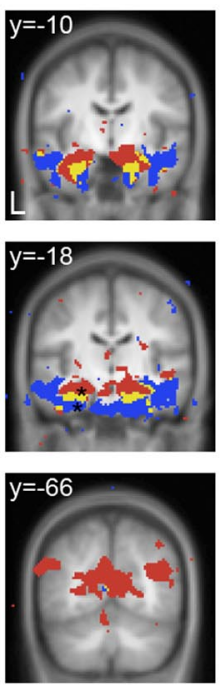

PRc/ERc

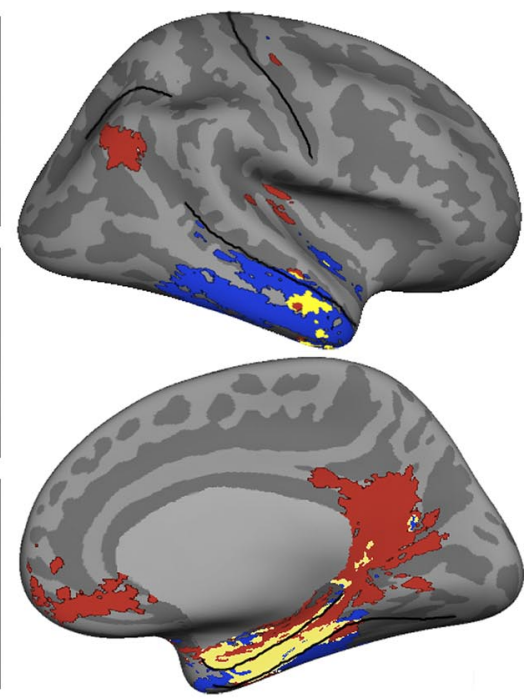

OVERLAP

FIG. 5. Distinct cortical regions are correlated with the perirhinal/entorhinal (PRc/ERc) and the body of the hippocampus (bHipp). Correlation maps are illustrated for 2 seed regions in the anterior part of the collateral sulcus (PRc/ERc) and in the hippocampus. A: PRc/ERc (MNI coordinates [-26 -20 - 30]) and bHipp $(-24-18-18)$ seeds defined as 3-mm spheres are depicted on coronal slices of group average T1-weighted MR images. An outline of the cortical gray matter is depicted below. Seed locations are depicted in black on coronal slices and as black stars on the cortical ribbon outline. Random effects maps $(P<$ 0.001 ) were obtained after within-subject transformation using Fisher's $r$-to- $z$ and submitted for a second level analysis. $B: 2$ distinct patterns of correlated cortical activity were observed. An overlap map for both left and right hemispheres demonstrates that the PRc/ERc was correlated with the anterior lateral temporal lobe (blue), the bHipp was correlated with lateral parietal, posterior cingulate/retrosplenial, as well as medial prefrontal cortices (red). Overlap in correlated activity is shown along the collateral sulcus (yellow). Note the close proximity of the seeds and consistent bilateral activation for both seeds.

are presented for both Data Set 1 and Data Set 2. As can be appreciated visually, both aITS and IPL reproducibly correlated with distinct subregions of the MTL. The reliability of MTL correlations with aITS and IPL can be observed by the similarity of random-effects $t$-maps obtained in Data Set 1 and Data Set 2 (Fig. 6).

To explicitly test whether aITS and IPL are differentially correlated with distinct subregions of MTL, we computed the correlation values from aITS and IPL with each of the anatomically defined seed regions in the MTL in Data Set 2 (Fig. 6, $C$ and $D$ ). Two-way $t$-test directly contrasted the correlation values of MTL subregions between the aITS and IPL. All $t$-tests were corrected for multiple comparisons using the Bonferroni method (Shaffer 1995). Results revealed reliably greater correlation values for the aITS relative to the IPL in the anterior hippocampus $\left[t(88)=5.72, P_{\text {corr }}<0.001\right]$, entorhinal/ perirhinal cortices $\left[t \mathrm{~s}(88)>4.66, P_{\text {corr }}<0.001\right]$, and the anterior aspect of the parahippocampal cortex $[t(88)=3.87$, $\left.P_{\text {corr }}<0.005\right]$. In contrast, reliably greater correlation values were observed for IPL relative to aITS in posterior parahippocampal cortex $\left[t(88)>3.80, P_{\text {corr }}<0.005\right]$. These results clearly demonstrate that the aITS and IPL reliably correlate with distinct subregions of the MTL.

\section{I S C U S S I O N}

Cortical pathways linked to distinct subregions of the MTL were explored using fMRI measurement of intrinsic activity (Biswal et al. 1995; Fox and Raichle 2007). By acquiring two data samples each with significant power, we were able to identify dissociated cortical pathways with a considerable degree of confidence and explore to what extent they converged with expectations from monkey anatomy. The main result of this paper is that we identified two separate cortical pathways that each associate with distinct subregions of the MTL.

The first pathway involves the anterior lateral temporal lobe, along the middle temporal gyrus immediately below the superior temporal sulcus (Fig. 4, left), and correlates with the perirhinal/entorhinal cortices. ${ }^{2}$ This pathway converges on the head of the hippocampus (Fig. 6, left). The second pathway involves the inferior parietal lobule, retrosplenial cortex, the posterior cingulate, and a portion of ventral medial prefrontal cortex (Fig. 4, right), and correlates with the posterior parahippocampal cortex. This second pathway converges on the body of the hippocampus (Fig. 6, right). The identification of these two pathways in humans provides both an anatomic reference to be used in future studies and also a basis to understand their distinct functional contributions as many studies in human focus on these cortical regions.

Using high-resolution whole-brain imaging, the present results extend previous reports that the MTL is correlated with widespread regions of cortex (Greicius et al. 2004; Vincent et al. 2006). By subdividing and completely covering the MTL it was observed that the brain regions associated with the MTL are comprised of two major brain pathways. Thus as predicted from anatomic studies in the monkey, two parallel pathways converge on distinct subregions of the MTL.

The presence of two pathways is broadly consistent with prior evidence from anatomical studies in non-human primates and rodents that emphasize parallel pathways distinguished by their input structure to parahippocampal cortex versus perirhi-

${ }^{2}$ While high-resolution functional imaging was used, the most ambiguous border for the approaches as applied here lies between perirhinal and entorhinal cortices. For this reason, we do not interpret strongly the present finding that entorhinal cortex tracked properties of perirhinal cortex and leave open the possibility that important topographical properties were not fully resolved. 

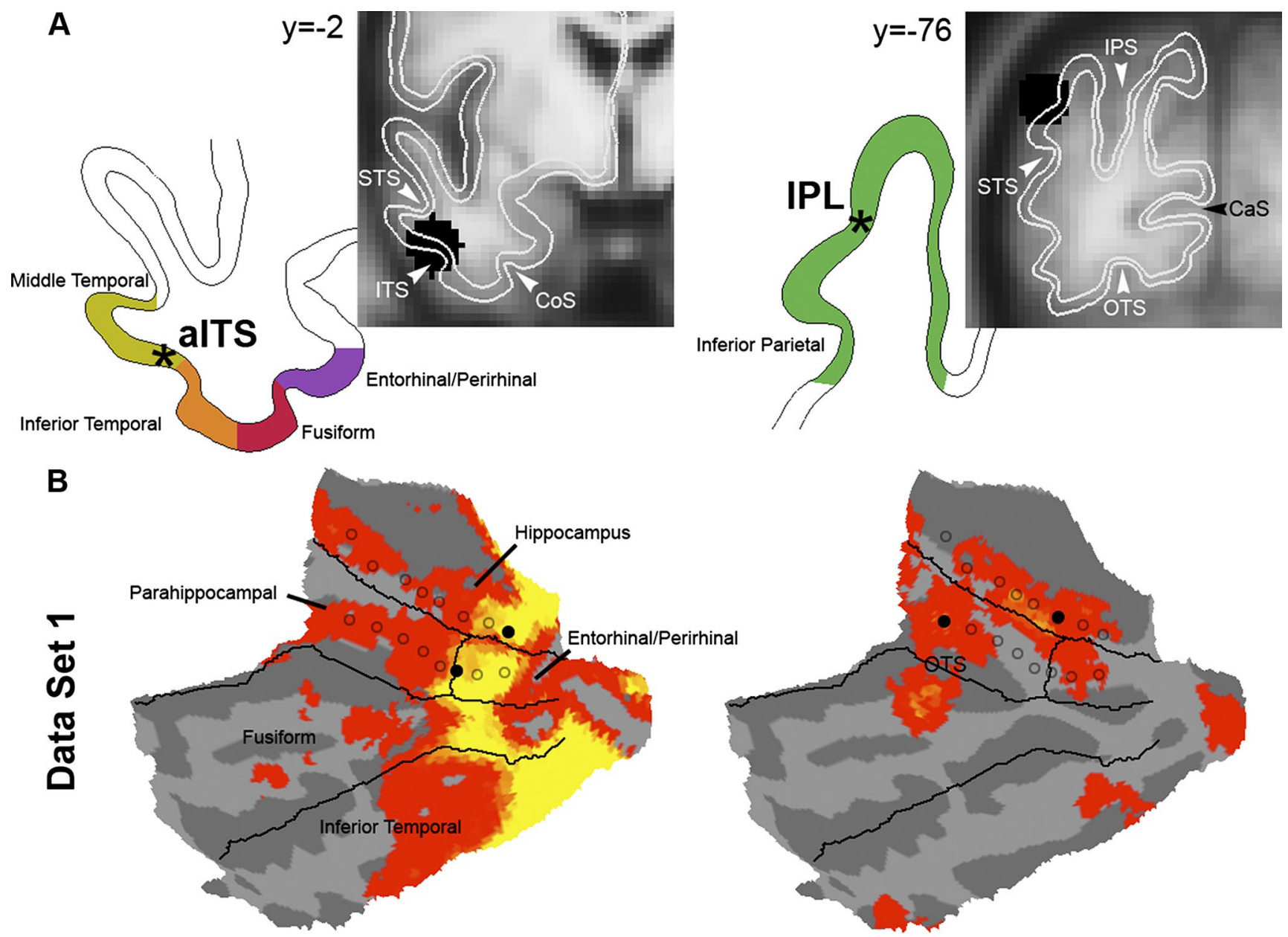

C
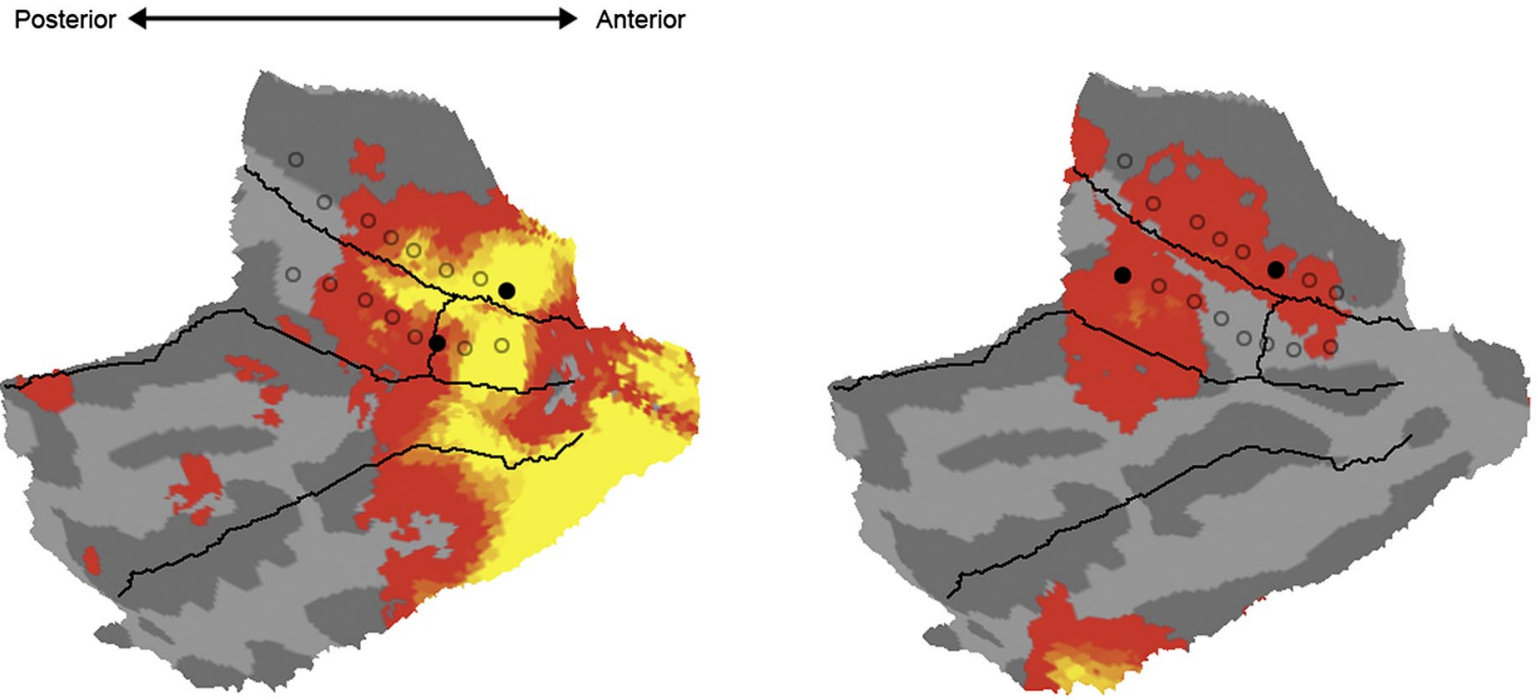

D

\begin{tabular}{|c|c|c|c|c|c|c|c|}
\hline-0.10 & -0.07 & -0.07 & -0.01 & 0.04 & 0.13 & 0.17 & 0.22 \\
\hline \multicolumn{8}{|c|}{ Hippocampus } \\
\hline 0.01 & 0.05 & 0.12 & 0.19 & 0.21 & 0.20 & 0.25 & 0.40 \\
\hline
\end{tabular}

\begin{tabular}{|llllllll|}
\hline$-\mathbf{0 . 1 0}$ & -0.04 & -0.02 & 0.00 & 0.03 & $\mathbf{0 . 1 2}$ & $\mathbf{0 . 1 0}$ & 0.03 \\
\hline
\end{tabular}

\begin{tabular}{|lllll|lll|}
\hline $\mathbf{0 . 1 5}$ & $\mathbf{0 . 1 8}$ & $\mathbf{0 . 1 6}$ & 0.08 & 0.03 & -0.01 & 0.01 & 0.04 \\
\hline
\end{tabular} 
nal cortex (postrhinal cortex in rodent) (Burwell and Amaral 1998; Lavenex and Amaral 2000; Suzuki and Amaral 1994a). Based on an analysis of MTL anatomical organization from an evolutionary perspective, Mann and Eichenbaum (2006) recently proposed that a fundamental role of the hippocampus is to combine information about spatial context from the parahippocampal cortex with nonspatial information about items from the perirhinal cortex (see also Diana et al. 2007; Eichenbaum et al. 2007). Our results are consistent with these ideas and also suggest how the domain of information being integrated may extend well beyond spatial information.

Specifically the distributed pathways converging on the hippocampus in humans include areas that likely represent highly processed amodal information although abstracted spatial representation cannot be fully discounted. The anterior lateral temporal cortex, including regions at or near the temporal pole, has been suggested to play an important role in processing of lexical and/or semantic components of language as well as processing social and emotional cues (for reviews, see Frith and Frith 2003; Olson et al. 2007). These regions have been implicated in semantic dementia (the temporal variant of frontotemporal dementia) (e.g., Hodges et al. 1992; Neary et al. 1998; Seeley et al. 2005). Functional neuroimaging studies that activate these or nearby regions often involve mentalizing (e.g., Castelli et al. 2000; Iacoboni et al. 2004; Mitchell et al. 2006; Saxe and Powell 2006), familiarity of faces and voices (e.g., Nakamura et al. 2000, 2001), semantics (e.g., Noppeney and Price 2002a,b; Vandenberghe et al. 2002), and autobiographical memory (e.g., Cabeza and St Jacques 2007; Maguire 2001; Svoboda et al. 2006). The relationship of these prior studies to the region identified here as correlated with the MTL memory system will require further study. The present results add to our understanding of anterior lateral temporal cortex by noting that this region is likely to be a connectional hub to the hippocampus by way of the perirhinal/entorhinal cortices.

The second pathway, involving retrosplenial cortex, posterior cingulate, IPL, and ventral medial prefrontal cortex has received considerable recent attention in the human literature because of its engagement during memory tasks including retrieval that emphasizes recollection (Wagner et al. 2005) and autobiographical memory (Svoboda et al. 2006). Recent studies have also suggested that this pathway is recruited when memory is used to construct episodic simulations of future events (Buckner and Carroll 2007; Hassabis and Maguire 2007; Schacter et al. 2007) and during default modes of cognition (Buckner et al. 2008; Gusnard and Raichle 2001).
The current findings provide two novel insights. First, this pathway is distinct from the anterior lateral temporal pathway noted in the preceding text. Many tasks concurrently activate both pathways (e.g., see the meta-analysis of 24 autobiographical memory studies of Svoboda et al. 2006). Thus future task-based studies should explore whether these two pathways can be systematically dissociated. Second, the pathway converges on the posterior portion of the parahippocampal cortex and the body of the hippocampus, which do not appear to strongly correlate with visual regions. While it is presently unclear how to accommodate this observation given past emphases on the importance of sensory convergence on the MTL, these new results raise the possibility that interactions with the MTL in humans are dominated by extrasensory areas.

In this light, it is important to note that the cortical systems interacting with the MTL have evolved considerably in humans. Van Essen and Dierker (2007) proposed, using interspecies surface-based registration and 23 functionally defined landmarks (see also, Orban et al. 2004), that multiple areal expansions are present in the human brain relative to the macaque. Notably, the inferior parietal lobule and lateral temporal lobe show extensive expansion. Further, an analysis of interspecies registration of macaque LVE areas (Lewis and Van Essen 2000) onto human suggests that macaque area TEc and TEr are shifted inferiorly in humans such that areas TEm and Ts (ST) are located along the superior temporal sulcus (Fig. 10 of Van Essen and Dierker 2007). The implications of this hypothesized reorganization and areal expansion for the present results is significant. Unlike non-human primates, where connectivity to the perirhinal cortex is predominantly visual (Suzuki and Amaral 1994a,b), it is possible that in humans the perirhinal cortex receives information that is expanded beyond that observed in macaque, receiving predominantly highly processed signals from regions of association cortex.

The candidate subdivisions and corresponding pathways will need to be verified with respect to anatomical connectivity using in vivo and ex vivo tracing methods, spontaneous BOLD correlations in nonhuman primates (e.g., Vincent et al. 2007), and functional organization derived from task manipulations. Nonetheless the present results provide a novel, robust dissociation of parallel pathways within the MTL memory system. The present results also highlight the importance of understanding the differences in connectivity and functionalanatomic organization between humans and non-human primates and rodents.

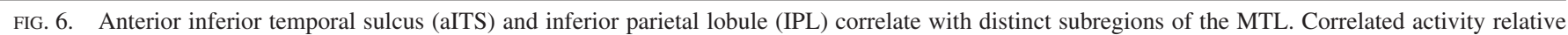

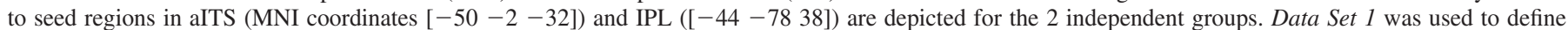

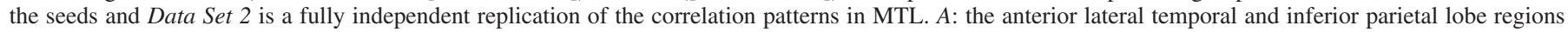

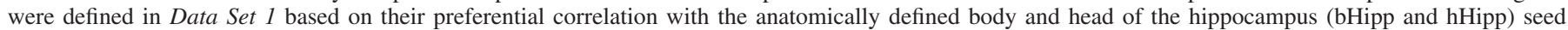

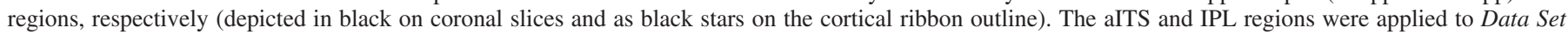

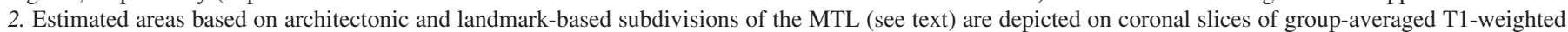

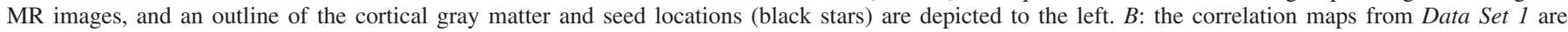

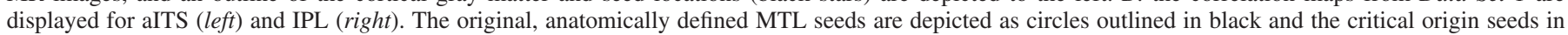

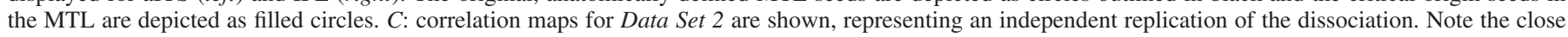

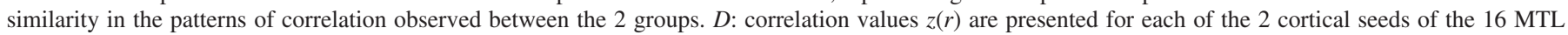

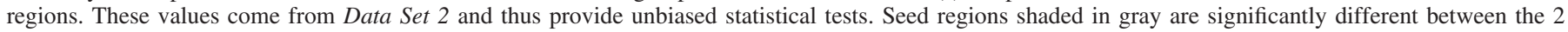

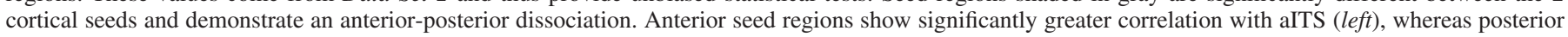
seed regions show greater correlation with IPL (right; all $P_{\text {corr }}<0.05$ ). Correlation values significantly different from 0 are in bold $\left(P_{\text {corr }}<0.05\right)$. 


\section{A C K N O W LEDGMENTS}

We thank J. Augustinack, D. Badre, and G. Wig for insightful comments and discussion and B. Fischl for providing Freesurfer software.

\section{G R A N T S}

This work was supported by National Institute on Aging Grant (AG021910) and Howard Hughes Medical Institute.

\section{REFERENCES}

Arieli A, Shoham D, Hildesheim R, Grinvald A. Coherent spatiotemporal patterns of ongoing activity revealed by real-time optical imaging coupled with single-unit recording in the cat visual cortex. J Neurophysiol 73: 2072-2093, 1995.

Bartels A, Zeki S. The chronoarchitecture of the cerebral cortex. Philos Trans $R$ Soc Lond 360: 733-750, 2005.

Birn RM, Diamond JB, Smith MA, Bandettini PA. Separating respiratoryvariation-related fluctuations from neuronal-activity-related fluctuations in fMRI. NeuroImage 31: 1536-1548, 2006.

Biswal B, Yetkin FZ, Haughton VM, Hyde JS. Functional connectivity in the motor cortex of resting human brain using echo-planar MRI. Magn Reson Med 34: 537-541, 1995.

Brainard DH. The Psychophysics Toolbox. Spatial Vision 10: 433-436, 1997.

Buckner RL, Andrews-Hanna JR, and Schacter DL. The brain's default network: anatomy, function, and relevance to disease. Ann NY Acad Sci 1124: 1-38, 2008.

Buckner RL, Carroll DC. Self-projection and the brain. Trends Cognit Sci 11: 49-57, 2007.

Buckner RL, Head D, Parker J, Fotenos AF, Marcus D, Morris JC, Snyder AZ. A unified approach for morphometric and functional data analysis in young, old, and demented adults using automated atlas-based head size normalization: reliability and validation against manual measurement of total intracranial volume. NeuroImage 23: 724-738, 2004.

Buckner RL, Petersen SE, Ojemann JG, Miezin FM, Squire LR, Raichle ME. Functional anatomical studies of explicit and implicit memory retrieval tasks. J Neurosci 15: 12-29, 1995.

Burwell RD. The parahippocampal region: corticocortical connectivity. Ann NY Acad Sci 911: 25-42, 2000.

Burwell RD, Amaral DG. Cortical afferents of the perirhinal, postrhinal, and entorhinal cortices of the rat. J Comp Neurol 398: 179-205, 1998.

Cabeza R, St Jacques P. Functional neuroimaging of autobiographical memory. Trends Cognit Sci 11: 219-227, 2007.

Castelli F, Happe F, Frith U, Frith C. Movement and mind: a functional imaging study of perception and interpretation of complex intentional movement patterns. Neurolmage 12: 314-325, 2000.

Catani M, Jones DK, Donato R, Ffytche DH. Occipito-temporal connections in the human brain. Brain 126: 2093-2107, 2003.

Cohen NJ, Eichenbaum HE. Memory, Amnesia, and the Hippocampal System. Cambridge, MA: The MIT Press, 1993.

De Luca M, Beckmann CF, De Stefano N, Matthews PM, Smith SM. fMRI resting state networks define distinct modes of long-distance interactions in the human brain. NeuroImage, 29: 1359-1367, 2006.

Desikan RS, Segonne F, Fischl B, Quinn BT, Dickerson BC, Blacker D, Buckner RL, Dale AM, Maguire RP, Hyman BT, Albert MS, Killiany RJ. An automated labeling system for subdividing the human cerebral cortex on MRI scans into gyral based regions of interest. NeuroImage 31: 968-980, 2006

Diana RA, Yonelinas AP, Ranganath C. Imaging recollection and familiarity in the medial temporal lobe: a three-component model. Trends Cognit Sci 11: 379-386, 2007.

Eichenbaum H, Yonelinas AP, Ranganath $\mathbf{C}$. The medial temporal lobe and recognition memory. Апnи Rev Neurosci 30: 123-152, 2007.

Fischl B, Salat DH, Busa E, Albert M, Dieterich M, Haselgrove C, van der Kouwe A, Killiany R, Kennedy D, Klaveness S, Montillo A, Makris N, Rosen B, Dale AM. Whole brain segmentation: automated labeling of neuroanatomical structures in the human brain. Neuron 33: 341-355, 2002.

Fischl B, Salat DH, van der Kouwe AJ, Makris N, Segonne F, Quinn BT, Dale AM. Sequence-independent segmentation of magnetic resonance images. NeuroImage 23 Suppl 1: S69-84, 2004.

Fischl B, Sereno MI, Tootell RB, Dale AM. High-resolution intersubject averaging and a coordinate system for the cortical surface. Hum Brain Mapp 8: 272-284, 1999.
Fox MD, Corbetta M, Snyder AZ, Vincent JL, Raichle ME. Spontaneous neuronal activity distinguishes human dorsal and ventral attention systems. Proc Natl Acad Sci USA 103: 10046-10051, 2006.

Fox MD, Raichle ME. Spontaneous fluctuations in brain activity observed with functional magnetic resonance imaging. Nat Rev Neurosci 8: 700-711, 2007.

Fox MD, Snyder AZ, Vincent JL, Corbetta M, Van Essen DC, Raichle ME. The human brain is intrinsically organized into dynamic, anticorrelated functional networks. Proc Natl Acad Sci USA 102: 9673-9678, 2005.

Frith U, Frith CD. Development and neurophysiology of mentalizing. Philos Trans R Soc Lond 358: 459-473, 2003.

Furtak SC, Wei S-M, Agster KL, Burwell RD. Functional neuroanatomy of the parahippocampal region in the rat: the perirhinal and postrhinal cortices. Hippocampus 17: 709-722, 2007.

Greicius MD, Krasnow B, Reiss AL, Menon V. Functional connectivity in the resting brain: a network analysis of the default mode hypothesis. Proc Natl Acad Sci USA 100: 253-258, 2003.

Greicius MD, Srivastava G, Reiss AL, Menon V. Default-mode network activity distinguishes Alzheimer's disease from healthy aging: evidence from functional MRI. Proc Natl Acad Sci USA 101: 4637-4642, 2004.

Gusnard DA, Raichle ME. Searching for a baseline: Functional imaging and the resting human brain. Nat Rev Neurosci 2: 685-694, 2001.

Hassabis D, Maguire EA. Deconstructing episodic memory with construction. Trends Cognit Sci 11: 299-306, 2007.

Hodges JR, Patterson K, Oxbury S, Funnell E. Semantic dementia. Progressive fluent aphasia with temporal lobe atrophy. Brain 115: 1783-1806, 1992.

Iacoboni M, Lieberman MD, Knowlton BJ, Molnar-Szakacs I, Moritz M, Throop CJ, Fiske AP. Watching social interactions produces dorsomedial prefrontal and medial parietal BOLD fMRI signal increases compared to a resting baseline. NeuroImage 21: 1167-1173, 2004.

Jenkinson M, Bannister P, Brady M, Smith S. Improved optimization for the robust and accurate linear registration and motion correction of brain images. Neurolmage 17: 825-841, 2002.

Jenkinson M, Smith S. A global optimisation method for robust affine registration of brain images. Medical Image Anal 5: 143-156, 2001.

Kenet T, Bibitchkov D, Tsodyks M, Grinvald A, Arieli A. Spontaneously emerging cortical representations of visual attributes. Nature 425: 954-956, 2003.

Lavenex P, Amaral DG. Hippocampal-neocortical interaction: a hierarchy of associativity. Hippocampus 10: 420-430, 2000.

Lewis JW, Van Essen DC. Mapping of architectonic subdivisions in the macaque monkey, with emphasis on parieto-occipital cortex. J Comp Neurol 428: 79-111, 2000.

Maguire EA. Neuroimaging studies of autobiographical event memory. Philos Trans $R$ Soc Lond 356: 1441-1451, 2001.

Manns JR, Eichenbaum H. Evolution of declarative memory. Hippocampus 16: 795-808, 2006.

Margulies DS, Kelly AM, Uddin LQ, Biswal BB, Castellanos FX, Milham MP. Mapping the functional connectivity of anterior cingulate cortex. NeuroImage 37: 579-588, 2007.

Milner B, Corkin S, Teuber HL. Further analysis of the hippocampal amnesia syndrome. Neuropsychologia 6: 215-234, 1968.

Mitchell JP, Macrae CN, Banaji MR. Dissociable medial prefrontal contributions to judgments of similar and dissimilar others. Neuron 50: 655-663, 2006.

Moon CH, Fukuda M, Park SH, Kim SG. Neural interpretation of blood oxygenation level-dependent fMRI maps at submillimeter columnar resolution. J Neurosci 27: 6892-6902, 2007.

Nakamura K, Kawashima R, Sato N, Nakamura A, Sugiura M, Kato T, Hatano K, Ito K, Fukuda H, Schormann T, Zilles K. Functional delineation of the human occipito-temporal areas related to face and scene processing. A PET study. Brain 123: 1903-1912, 2000.

Nakamura K, Kawashima R, Sugiura M, Kato T, Nakamura A, Hatano K, Nagumo S, Kubota K, Fukuda H, Ito K, Kojima S. Neural substrates for recognition of familiar voices: a PET study. Neuropsychologia 39: 10471054, 2001.

Neary D, Snowden JS, Gustafson L, Passant U, Stuss D, Black S, Freedman M, Kertesz A, Robert PH, Albert M, Boone K, Miller BL, Cummings J, Benson DF. Frontotemporal lobar degeneration: a consensus on clinical diagnostic criteria. Neurology 51: 1546-1554, 1998.

Noppeney U, Price CJ. A PET study of stimulus- and task-induced semantic processing. NeuroImage 15: 927-935, 2002a. 
Noppeney U, Price CJ. Retrieval of visual, auditory, and abstract semantics. NeuroImage 15: 917-926, 2002b.

Ojemann JG, Akbudak E, Snyder AZ, McKinstry RC, Raichle ME, Conturo TE. Anatomic localization and quantitative analysis of gradient refocused echo-planar fMRI susceptibility artifacts. NeuroImage 6: 156167, 1997.

Olson IR, Plotzker A, Ezzyat Y. The Enigmatic temporal pole: a review of findings on social and emotional processing. Brain 130: 1718-1731, 2007.

Orban GA, Van Essen D, Vanduffel W. Comparative mapping of higher visual areas in monkeys and humans. Trends Cognit Sci 8: 315-324, 2004.

Saxe R, Powell LJ. It's the thought that counts: specific brain regions for one component of theory of mind. Psychol Sci 17: 692-699, 2006.

Schacter DL, Addis DR, Buckner RL. Remembering the past to imagine the future: the prospective brain. Nat RevNeurosci 8: 657-661, 2007.

Schmahmann JD, Pandya DN. Fiber Pathways of the Brain. Oxford, UK: Oxford Univ. Press, 2006.

Seeley WW, Bauer AM, Miller BL, Gorno-Tempini ML, Kramer JH, Weiner M, Rosen HJ. The natural history of temporal variant frontotemporal dementia. Neurology 64: 1384-1390, 2005.

Shaffer JP. Multiple Hypothesis Testing. Annu Rev Psychol 46: 561-584, 1995.

Squire LR. Memory and the hippocampus: A synthesis from findings with rats, monkeys, and humans. Psychol Rev 99: 195-231, 1992.

Squire LR, Stark CE, Clark RE. The medial temporal lobe. Annu Rev Neurosci 27: 279-306, 2004.

Suzuki WA, Amaral DG. Perirhinal and parahippocampal cortices of the macaque monkey: cortical afferents. J Comp Neurol 350: 497-533, 1994a.
Suzuki WA, Amaral DG. Topographic organization of the reciprocal connections between the monkey entorhinal cortex and the perirhinal and parahippocampal cortices. J Neurosci 14: 1856-1877, 1994 b.

Svoboda E, McKinnon MC, Levine B. The functional neuroanatomy of autobiographical memory: a meta-analysis. Neuropsychologia 44: 21892208, 2006.

Van Essen DC. A Population-Average, Landmark- and Surface-based (PALS) atlas of human cerebral cortex. NeuroImage 28: 635-662, 2005.

Van Essen DC, Dierker DL. Surface-based and probabilistic atlases of primate cerebral cortex. Neuron 56: 209-225, 2007.

Vandenberghe R, Nobre AC, Price CJ. The response of left temporal cortex to sentences. J Cognit Neurosci 14: 550-560, 2002.

Vincent JL, Patel GH, Fox MD, Snyder AZ, Baker JT, Van Essen DC, Zempel JM, Snyder LH, Corbetta M, Raichle ME. Intrinsic functional architecture in the anaesthetized monkey brain. Nature 447: 83-86, 2007.

Vincent JL, Snyder AZ, Fox MD, Shannon BJ, Andrews JR, Raichle ME, Buckner RL. Coherent spontaneous activity identifies a hippocampalparietal memory network. J Neurophysiol 96: 3517-3531, 2006.

Wagner AD, Shannon BJ, Kahn I, Buckner RL. Parietal lobe contributions to episodic memory retrieval. Trends Cognit Scie 9: 445-453, 2005.

Wise RG, Ide K, Poulin MJ, Tracey I. Resting fluctuations in arterial carbon dioxide induce significant low frequency variations in BOLD signal. $\mathrm{Neu}$ roImage 21: 1652-1664, 2004.

Witter MP, Naber PA, van Haeften T, Machielsen WC, Rombouts SA, Barkhof F, Scheltens P, Lopes da Silva FH. Cortico-hippocampal communication by way of parallel parahippocampal-subicular pathways. Hippocampus 10: 398-410, 2000.

Zar J. Biostatistical Analysis. Upper Saddle River, NJ: Prentice-Hall, 1996. 